\title{
Effect of Pore Size Distribution and Amination on Adsorption Capacities of Polymeric Adsorbents
}

\author{
Wei Liu *, Yuxi Zhang, Shui Wang, Lisen Bai, Yanhui Deng and Jingzhong Tao
}

Citation: Liu, W.; Zhang, Y.;

Wang, S.; Bai, L.; Deng, Y.; Tao, J.

Effect of Pore Size Distribution and

Amination on Adsorption Capacities of Polymeric Adsorbents. Molecules 2021, 26, 5267. https://doi.org/ $10.3390 /$ molecules 26175267

Academic Editors: Giorgio Vilardi and Chiara Bisio

Received: 16 July 2021

Accepted: 25 August 2021

Published: 30 August 2021

Publisher's Note: MDPI stays neutral with regard to jurisdictional claims in published maps and institutional affiliations.

Copyright: (c) 2021 by the authors. Licensee MDPI, Basel, Switzerland. This article is an open access article distributed under the terms and conditions of the Creative Commons Attribution (CC BY) license (https:/ / creativecommons.org/licenses/by/ $4.0 /)$.
Jiangsu Key Laboratory of Environmental Engineering, Jiangsu Academy of Environmental Sciences, 176\# Jiangdong Beilu Road, Nanjing 210036, China; zhangyuxiNJU@163.com (Y.Z.); ws@vip.sina.com (S.W.); bailisen23@163.com (L.B.); jsshkylw@163.com (Y.D.); jshbtao@126.com (J.T.)

* Correspondence: liuwei@smail.nju.edu.cn or jshblw@126.com; Tel.: +86-025-58527708

\begin{abstract}
Polymeric adsorbents with different properties were synthesized via suspension polymerization. Equilibrium and kinetics experiments were then performed to verify the adsorption capacities of the resins for molecules of various sizes. The adsorption of small molecules reached equilibrium more quickly than the adsorption of large molecules. Furthermore, the resins with small pores are easy to lower their adsorption capacities for large molecules because of the pore blockage effect. After amination, the specific surface areas of the resins decreased. The average pore diameter decreased when the resin was modified with either primary or tertiary amines, but the pore diameter increased when the resin was modified with secondary amines. The phenol adsorption capacities of the amine-modified resins were reduced because of the decreased specific area. The amine-modified resins could more efficiently adsorb reactive brilliant blue 4 owing to the presence of polar functional groups.
\end{abstract}

Keywords: resin; adsorption; pore size distribution; chemical modification; water treatment

\section{Introduction}

Nowadays, large amounts of wastewater containing pollutants such as pesticides, dyes, heavy metals, and pharmaceuticals have been produced because of increased agricultural applications and the growth of the pharmaceutical and chemical industries [1]. Effluent containing even low concentrations of organic contaminants can be highly discernible and recalcitrant [2]. The large-scale production and widespread use of chemical substances can cause serious environmental problems, making it an important public concern [3]. Thus, the effective removal of organic pollutants from water sources is necessary for environmental security and public health.

Adsorption is a low-energy solid phase extraction technique that has been widely applied in industry in recent years. Various materials have been used as adsorbents, including mesoporous silica, natural zeolites and activated carbons [4,5]. However, these materials have some disadvantages that limit their application, such as unfavorable selective adsorption or poor regeneration [6].

Since the 1970s, functional polymers that have adsorption and separation capability have rapidly developed, and adsorbent resins have been widely used in various fields. Resins can adsorb organic matter through non-covalent bonding between molecules. The adsorbed molecules can then be eluted, thereby regenerating the resin to achieve the enrichment, separation and recovery of organic matter in wastewater [7-9]. For example, Zhu Shiyun et al. [10] used the strong anionic resin Amberlite IRA 402-OH to remove acetaldehyde from petrochemical production wastewater. The acetaldehyde removal efficiency from wastewater was $86 \%$.

Adsorbent resins have been widely used to remove in dyes chemicals (such as benzene and naphthalene), pharmaceutical intermediates, and other organic compounds from wastewater [11]. Although existing adsorption resins can efficiently remove micromolecules and low water-soluble organic matter from wastewater, they are not effective 
for the adsorption of large molecules or organic matter with complex molecular structures. Therefore, a series of resins with different pore size distributions and high-adsorption capacity chemical groups were synthesized to address this problem. The adsorption behavior and effects on adsorption properties were studied.

Adsorbent resins can be synthesized via addition polymerization and condensation polymerization. The design of the pore structure in the resin synthesis is important and includes the pore volume, pore size, pore distribution, and specific surface area [12] Many factors can affect the pore structure. For instance, when synthesizing macroporous adsorbents, the polarity, pore size, pore distribution, and specific surface area of the resin can be adjusted by controlling the polymerization conditions, such as the crosslinking agent, amount and type of porogen, and monomer composition $[13,14]$. The pore structure plays an important role in the adsorption ability of resins.

In addition to the pore diameter, the chemical structure of the resin also has an important effect on its adsorption properties. Li et al. [15] carbonized XAD-4 resin and found that the modified resin had good adsorption of phenolic compounds. Huang et al. [16] synthesized a new diethylenetriamine-modified hyper-cross-linked polystyrene resin with improved adsorptive removal of phenol. Li et al. [17] synthesized anion-exchange resins with different trialkylammonium groups, which significantly improved the nitrate adsorption capacity and improved the humic acid anti-fouling performance. Thus, we modified synthesized resins with amines and increase the resins adsorption for stronger polar and bigger molecules.

\section{Materials and Methods}

\subsection{Chemicals}

Divinylbenzene (DVB, 83.5\%) and divinylbenzene (DVB, 50.0\%) was purchased from Shandong Dongda Chemicals Company (Shandong, China) which were used as monomers. Toluene ( $>99.7 \%$, Shanghai Chemical Reagent Company), liquid wax $(>99.5 \%$, Shanghai Chemical Reagent Company), n-heptane ( $>99.7 \%$, Shandong Dongda Chemicals Company) and hexadecanol ( $>99.7 \%$, Shanghai Chemical Reagent Company) were used as porogen. Gelatin (Photographic grade) was purchased from Yancheng Dafeng Gelatin Company (Jiangsu, China). Benzoyl peroxide ( $>99.7 \%$, Shanghai Chemical Reagent Company) was used as an initiator. Zinc chloride ( $>99.7 \%$ ) as the catalyst for chloromethylation were purchased from Shanghai Chemical Reagent Company. Chloromethyl ether ( $>99.7 \%$, Shanghai Chemical Reagent Company), chloroform ( $>99.7 \%$, Nanjing Chemical Reagent Company) and methylal $(>99.7 \%$, Shanghai Chemical Reagent Company) were used as the swelling agent. Hexamethylenetetramine $(>99.7 \%)$, methylamine aqueous solution $(25 \%)$ and dimethylamine aqueous solution $(33 \%)$ used for amino-modified were all purchased from Nanjing Chemical Reagent Company. $\mathrm{HCl}$ and $\mathrm{NaOH}$ were obtained from Shanghai Chemical Reagent Company. Phenol (>99.7\%), 1-amino-4- bromoanthraquinone-2sulfonic acid (ABS acid, >99.7\%), and reactive brilliant blue 4 (RBB4, > $99.5 \%$ ) used as adsorbates were also purchased from Nanjing Chemical Reagent Company. Their structure and molecular sizes of them were estimated by WinMopac7.21, and the results are shown in Figure S1.

\subsection{Preparation}

An aqueous phase $(200.0 \mathrm{~g})$ solution consisting of $1 \%$ gelatin and an oil phase consisting of divinylbenzene (DVB, $83.5 \%$ or $50.0 \%$ ), benzoyl peroxide (initiator) and different porogen were added to a $500-\mathrm{mL}$ flask. The stirring speed was $300 \mathrm{rpm}$. The temperature was gradually increased to $80^{\circ} \mathrm{C}$ for $3 \mathrm{~h}$, then to $85^{\circ} \mathrm{C}$ for $4 \mathrm{~h}$, and finally to $95^{\circ} \mathrm{C}$ for $4 \mathrm{~h}$. After cooling for $2 \mathrm{~h}$, the polymer beads were filtered with glass sand core vacuum filtration apparatus (50 mesh) and washed with hot water $\left(60^{\circ} \mathrm{C}\right)$. The obtained resins were NDA- 1 , NDA-2, NDA-3, NDA-4 and NDA-1800 for different monomer concentrations, porogen proportion and monomer: porogen ratio. All the polymer beads were then extracted with acetone in a Soxhlet extractor for $8 \mathrm{~h}$, following by vacuum drying for $8 \mathrm{~h}$ at $60^{\circ} \mathrm{C}$ under a 
$10 \mathrm{mmHg}$ vacuum, respectively. The reaction process, final product and corresponding reagents are shown in Figure 1 and Table S1.

Then, the primary aminated resin (NDA-1801), the secondary aminated resin (NDA1802 ) and the tertiary aminated resin (NDA-1803) were prepared, respectively. NDA1800 resin $(300.0 \mathrm{~g})$ was chloromethylated with chloromethyl ether (1800.0 g) by using zinc chloride $(180.0 \mathrm{~g})$ as the catalyst. For NDA-1801 preparation, the chloromethylated NDA-1800 resin $(80.0 \mathrm{~g})$ was then emerged in chloroform $(120 \mathrm{~mL})$ for $2 \mathrm{~h}$, and then hexamethylenetetramine aqueous solution $(50.0 \%, 331.7 \mathrm{~g})$ was added. The $\mathrm{pH}$ value was adjusted to 12.0 with $\mathrm{NaOH}(10 \mathrm{~mol} / \mathrm{L})$. For the preparation of NDA-1802, NDA-1800 resin $(80.0 \mathrm{~g})$ was swelled in methylal $(120 \mathrm{~g}) 2 \mathrm{~h}$, and then the methylamine aqueous solution $(25 \%)$ was added. The $\mathrm{pH}$ was adjusted to 12 with $\mathrm{NaOH}(10 \mathrm{~mol} / \mathrm{L})$. The solution was then incubated at $45^{\circ} \mathrm{C}$ for $10 \mathrm{~h}$. For the preparation of NDA-1803, NDA-1800 resin (80.0 g) was also swelled in methylal $(120 \mathrm{~g}) 2 \mathrm{~h}$. Then, the dimethylamine aqueous solution (33\%) was added, and the $\mathrm{pH}$ was adjusted to 12 with $\mathrm{NaOH}(40 \%)$. The solution was incubated at $45^{\circ} \mathrm{C}$ for $10 \mathrm{~h}$. After the amination, all the obtained beads were washed with deionized water until the $\mathrm{pH}$ was neutral.

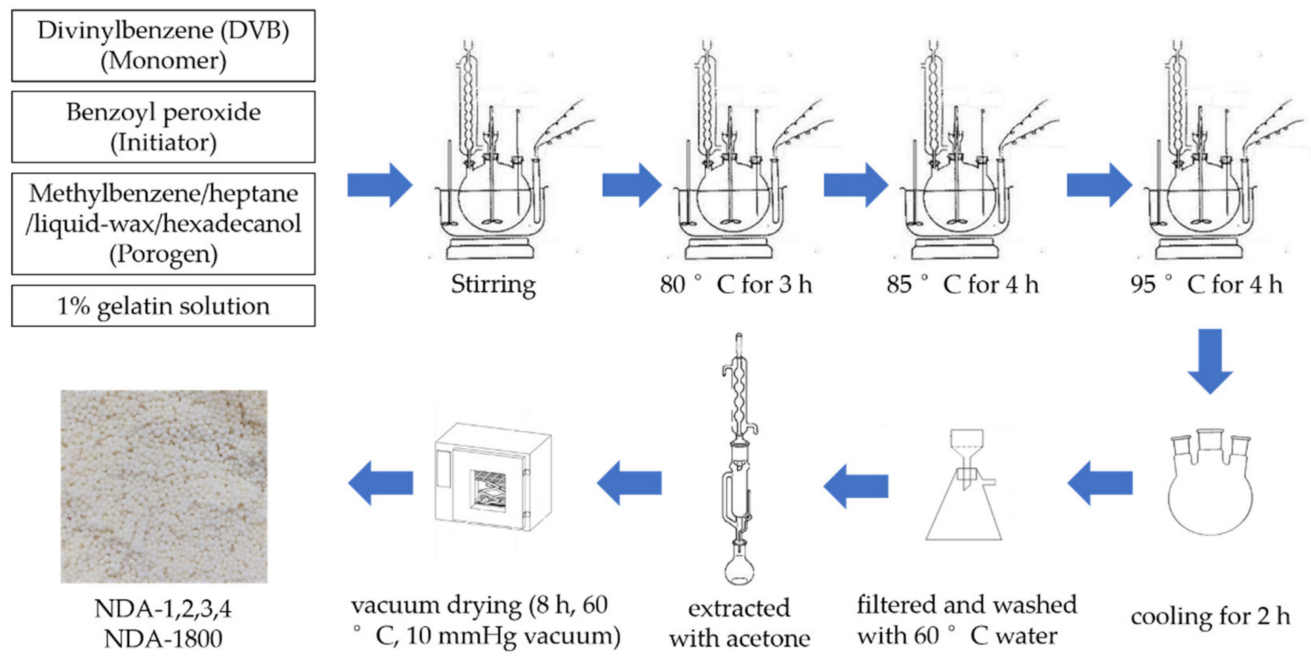

Figure 1. The flow diagram of resin synthesis.

\subsection{Characterization}

The BET surface area $\left(\mathrm{S}_{\mathrm{BET}}\right)$ of the resin was calculated using the isothermal adsorption and desorption experiments of $\mathrm{N}_{2}$ at $77 \mathrm{~K}$. The micropore volume $\left(\mathrm{V}_{\text {micro }}\right)$ and the micropore area $\left(\mathrm{S}_{\text {micro }}\right)$ were determined by the $\mathrm{t}$-plot method [18]. When the relative pressure is close to 1 ( 0.98 in this experiment), the $\mathrm{N}_{2}$ adsorption amount $\left(\mathrm{V}_{\mathrm{t}}\right)$ corresponds to the total adsorption amount of micropores and mesopores in the resin. The mesopore volume $\left(\mathrm{V}_{\text {meso }}\right)$ of the resin can be obtained by subtracting $\mathrm{V}_{\text {micro }}$ from the adsorption amount at this time. The average pore diameter in the mesoporous region was obtained through a BJH desorption experiment. The whole process was completed automatically by an accelerated surface area and porosimeter system (ASAP 2010, Micromeritics, Georgia USA). The exchange capacity was determined by acid-base titration. The pretreated resin was soaked in the $\mathrm{HCl}$ aqueous solution, and the capacity was obtained by $\mathrm{NaOH}$ titration of the residual $\mathrm{HCl}$ in the solution with phenolphthalein [19]. Fourier transform infrared (FTIR) spectroscopy was performed with an FTIR spectrophotometer (Nicolet 170 SX, Georgia USA) via $\mathrm{KBr}$ pressed-disk technique.

\subsection{Adsorption Kinetics}

A $0.1000 \mathrm{~g}$ aliquot of resin was accurately weighed into a $250-\mathrm{mL}$ conical flask, and $100 \mathrm{~mL}$ of preheated ( $303 \mathrm{~K}$ ) $500 \mathrm{mg} \cdot \mathrm{L}^{-1}$ aqueous solution of adsorbate was added. The flask was sealed and placed on a constant temperature shaker set at $303 \mathrm{~K}$ and shaken 
at $130 \mathrm{rpm}$. Samples were removed at regular intervals to measure the concentration of the adsorbates via a high-performance liquid chromatography (Waters 600) and a UV-vis spectrophotometer (GBC UV/VIS 916).

\subsection{Static Equilibrium Adsorption}

A $0.1000 \mathrm{~g}$ aliquot of resin was weighed into a $250-\mathrm{mL}$ conical flask. Different concentrations of adsorbate solution $(100 \mathrm{~mL})$ were added, and the mixtures were shaken for $48 \mathrm{~h}$ on a constant temperature shaker at $303 \mathrm{~K}$ and $130 \mathrm{rpm}$. The solute concentrations in the equilibrated solutions were then analyzed.

\subsection{Analysis}

Phenol was determined by a high-performance liquid chromatography (Waters 600). ABS acid and RBB4 were determined by a UV-vis spectrophotometer (GBC UV/VIS 916) at $486 \mathrm{~nm}$ and $605 \mathrm{~nm}$, respectively.

The equilibrium adsorption capacity $\left(Q_{e}\left(\mathrm{mmol} \cdot \mathrm{g}^{-1}\right)\right)$ was calculated as follows:

$$
Q_{e}=\frac{V_{1}\left(C_{0}-C_{e}\right)}{M W}
$$

where, $V_{1}(\mathrm{~L})$ is the volume of the solution, $W(\mathrm{~g})$ is the mass of the dry resin, and $M$ is the molar mass of the adsorbate molecule.

\section{Results and Discussion}

\subsection{Characterization}

The specific surface area and pore structure of the synthesized resins (NDA-1, NDA-2, NDA-3, and NDA-4) were measured. Their specific surface areas ranged from 448.0 to $565.1 \mathrm{~m}^{2} \cdot \mathrm{g}^{-1}$.

The characterization results of the resins are shown in Table 1. The mesopore diameter distribution was calculated using the Barret-Joyner-Halenda (BJH) method, as shown in Figure 2. NDA-2 had the largest specific surface area, and the other three resins had similar specific surface areas. The pore diameter distributions of NDA-1 and NDA-2 were relatively narrow, but those of NDA-3 and NDA-4 were relatively wide.

Table 1. Characterization of resins.

\begin{tabular}{|c|c|c|c|c|c|c|c|c|c|}
\hline \multirow{2}{*}{ Number } & \multicolumn{3}{|c|}{ Specific Surface Area $\left(\mathrm{m}^{2} \cdot \mathrm{g}^{-1}\right)$} & \multirow{2}{*}{$\mathrm{S}_{\mathrm{ext}} \%$} & \multicolumn{3}{|c|}{ Pore Volume $\left(\mathrm{cm}^{3} \cdot \mathrm{g}^{-1}\right)$} & \multirow{2}{*}{$V_{\text {meso }} \%$} & \multirow{2}{*}{$\begin{array}{l}\text { Average Pore } \\
\text { Diameter (nm) }\end{array}$} \\
\hline & $\mathrm{S}_{\mathrm{BET}}$ & $S_{\text {micro }}$ & $S_{\text {ext }}$ & & $\mathbf{V}_{\mathrm{t}}$ & $\mathbf{V}_{\text {micro }}$ & $\mathrm{V}_{\text {meso }}$ & & \\
\hline NDA-1 & 448.0 & 37.2 & 410.8 & 91.7 & 0.310 & 0.0098 & 0.3002 & 96.8 & 3.80 \\
\hline NDA-2 & 565.1 & 51.8 & 513.3 & 90.8 & 0.474 & 0.0148 & 0.4592 & 96.9 & 4.74 \\
\hline NDA-3 & 452.4 & 43.1 & 409.3 & 90.5 & 0.736 & 0.0213 & 0.7147 & 97.1 & 6.87 \\
\hline NDA-4 & 486.6 & 32.4 & 454.2 & 93.3 & 0.767 & 0.0091 & 0.7579 & 98.8 & 6.72 \\
\hline
\end{tabular}

Note: $S_{B E T}, S_{\text {micro }}$ and $S_{\text {ext }}$ are the BET specific surface area, micropore area and non-micropore area, respectively. $V_{t}, V_{\text {micro }}$ and $V_{\text {meso }}$ are the pore volume, micropore volume and meso-pore volume, respectively, when the relative pressure was 0.98 . $S_{\text {ext }} \%$ and $V_{\text {meso }} \%$ are the percentage of the specific surface area of non-micropores and the percentage of the mesopore volume, respectively.

The $\mathrm{N}_{2}$ adsorption isotherms of the synthetic resins were mostly II and IV hybrid adsorption isotherms (see Figure 3). Micropore filling occurred when relative pressure $\left(\mathrm{p} / \mathrm{p}_{0}\right)$ was between 0.0 to 0.2 and the adsorption was low. When the relative pressure was slightly higher, the hysteresis curve appeared between the adsorption and desorption curves owing to the occurrence of multilayer adsorption and capillary condensation, indicating that most pores in the resins were mesopores [20]. The low range isotherms (at the logarithmic scale $\left(\mathrm{p} / \mathrm{p}_{0}\right)$ scale) were also presented in supporting information (Figure S2). 


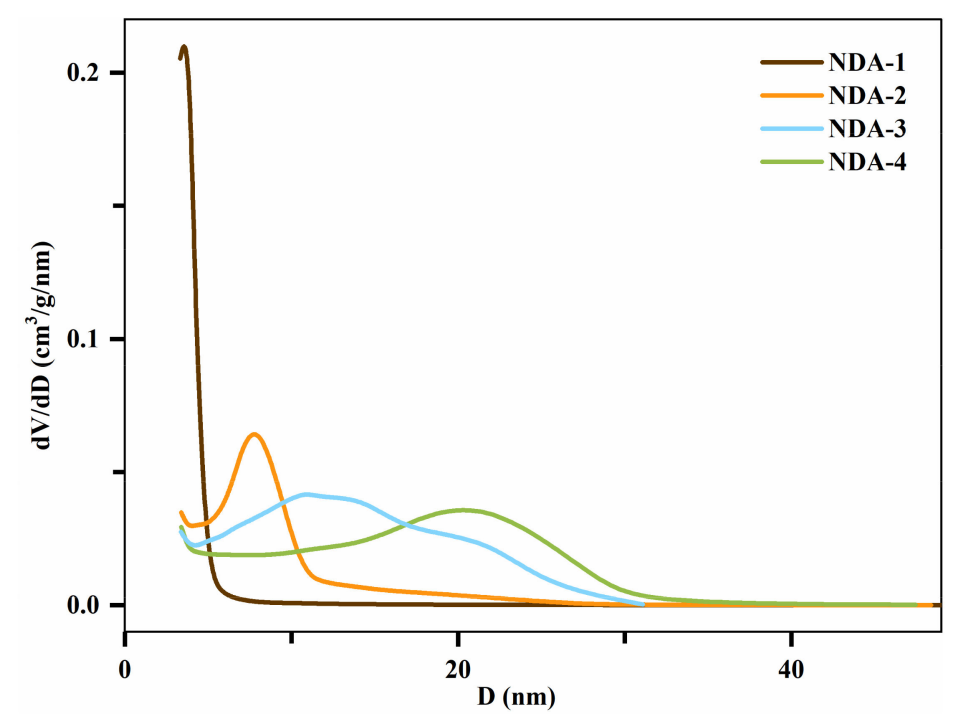

Figure 2. Mesopore diameter distribution of NDA-1, NDA-2, NDA-3, and NDA-4.
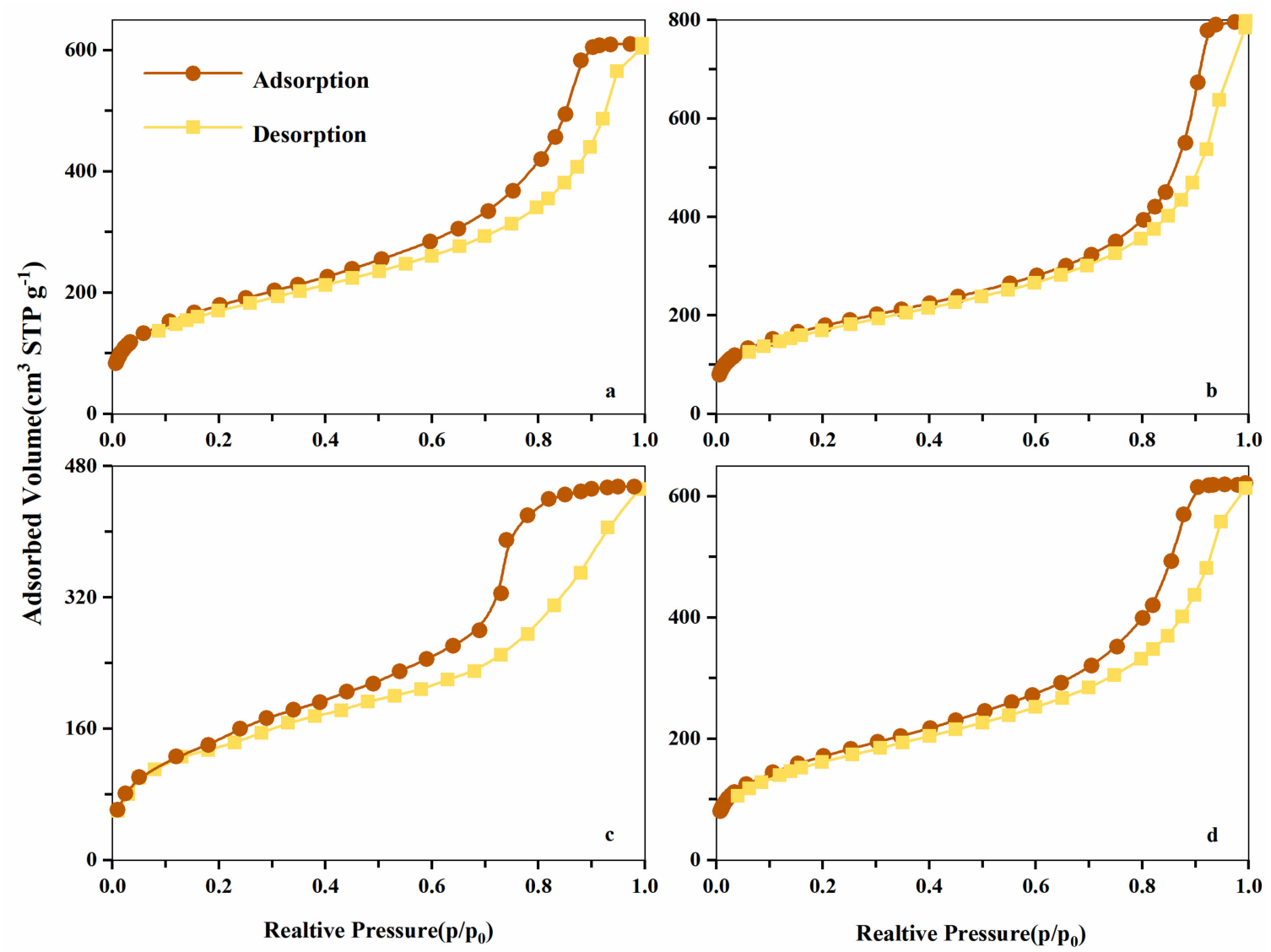

Figure 3. $\mathrm{N}_{2}$ adsorption isotherms of NDA-1 (a), NDA-2 (b), NDA-3 (c) and NDA-4 (d) resins at $77 \mathrm{~K}$.

After modification of NDA-1800 with amines, their characterizations were determined. The infrared spectra of NDA-1800, NDA-1801, NDA-1802, and NDA-1803 resins are shown in Figure S3. Compared with the NDA-1800 resin, the resins modified by primary amines, secondary amines and tertiary amines had a very small peak around $672 \mathrm{~cm}^{-1}$; this was attributed to the chloromethyl peak. The peaks appearing near $1040 \mathrm{~cm}^{-1}$ and $1118 \mathrm{~cm}^{-1}$ were designated as $\mathrm{C}-\mathrm{N}$ stretching vibration peaks, and they were not present for NDA1800. In the modified resins, the peaks around $3445 \mathrm{~cm}^{-1}$ were N-H stretching vibration peaks, which indicated that amine groups had been successfully introduced to the three 
modified resins. Moreover, the chloride content of the resin after amination was decreased, indicating that the chlorine had been partly replaced by the amino groups (Table 2). The exchange capacities of the three modified resins were $1.3,1.49$, and $5.4 \mathrm{mmol} \cdot \mathrm{g}^{-1}$ for NDA1801, NDA-1802, and NDA-1803, effectively, showing that the number of exchangeable amino groups increased on the resin skeleton after reaction. Therefore, when contacted by adsorbate, the resins could provide exchange sites and electrostatic adsorption sites in addition to the $\pi-\pi$ interactions of the resin skeleton.

Table 2. Characterization of the modified resins.

\begin{tabular}{|c|c|c|c|c|c|c|c|c|c|c|}
\hline \multirow{2}{*}{ Number } & \multicolumn{2}{|c|}{$\begin{array}{l}\text { Specific Surface } \\
\text { Area }\left(\mathrm{m}^{2} \cdot \mathrm{g}^{-1}\right)\end{array}$} & \multicolumn{2}{|c|}{$\begin{array}{l}\text { Pore Volume } \\
\left(\mathrm{cm}^{3} \cdot \mathrm{g}^{-1}\right)\end{array}$} & \multirow{2}{*}{$\begin{array}{l}\text { Average Pore } \\
\text { Diameter (nm) }\end{array}$} & \multirow{2}{*}{$\begin{array}{l}\text { Modification } \\
\text { Methods }\end{array}$} & \multirow[t]{2}{*}{ Polarity } & \multirow{2}{*}{$\begin{array}{c}\text { Mean } \\
\text { Particle } \\
\text { Size }(\mathrm{mm})\end{array}$} & \multirow{2}{*}{$\begin{array}{l}\text { Residual } \\
\text { Chlorine } \\
\text { Content (\%) }\end{array}$} & \multirow{2}{*}{$\begin{array}{c}\text { Total Exchange } \\
\text { Capacity } \\
\left(\mathrm{mmol}^{-1} \mathrm{~g}^{-1)}\right.\end{array}$} \\
\hline & $\mathrm{S}_{\text {BET }}$ & $\mathrm{S}_{\text {micro }}$ & $V_{t}$ & $\mathrm{~V}_{\text {micro }}$ & & & & & & \\
\hline NDA-1800 & 852.3 & 93.3 & 1.470 & 0.022 & 7.47 & / & nonpolar & $0.4-0.6$ & I & / \\
\hline NDA-1801 & 630.6 & 84.1 & 0.944 & 0.021 & 5.99 & $\begin{array}{l}\text { Primary } \\
\text { amine }\end{array}$ & polar & $0.4-0.6$ & 6.8 & 1.13 \\
\hline NDA-1802 & 628.4 & 54.7 & 1.230 & 0.009 & 7.86 & $\begin{array}{l}\text { Secondary } \\
\text { amine }\end{array}$ & polar & $0.4-0.6$ & 7.1 & 1.49 \\
\hline NDA-1803 & 602.6 & 59.0 & 0.961 & 0.010 & 6.38 & $\begin{array}{l}\text { Tertiary } \\
\text { amine }\end{array}$ & polar & $0.4-0.6$ & 5.4 & 5.40 \\
\hline
\end{tabular}

The data in Table 2 show that compared with NDA-1800, the specific surface areas of the resins modified with primary amines, secondary amines and tertiary amines were $26.0 \%$, $26.3 \%$, and $29.3 \%$ smaller, respectively. This was because during chloromethylation some part of the resin pores collapsed owing to the swelling action of chloromethyl ether, resulting in a decreased specific surface area. Figure 4 shows that the pore diameter of the resins also changed after modification with amine groups. The concentration pore diameters of resins modified with primary amines and tertiary amines slightly decreased to approximately $14 \mathrm{~nm}$, while that of the resin modified with secondary amines slightly increased.

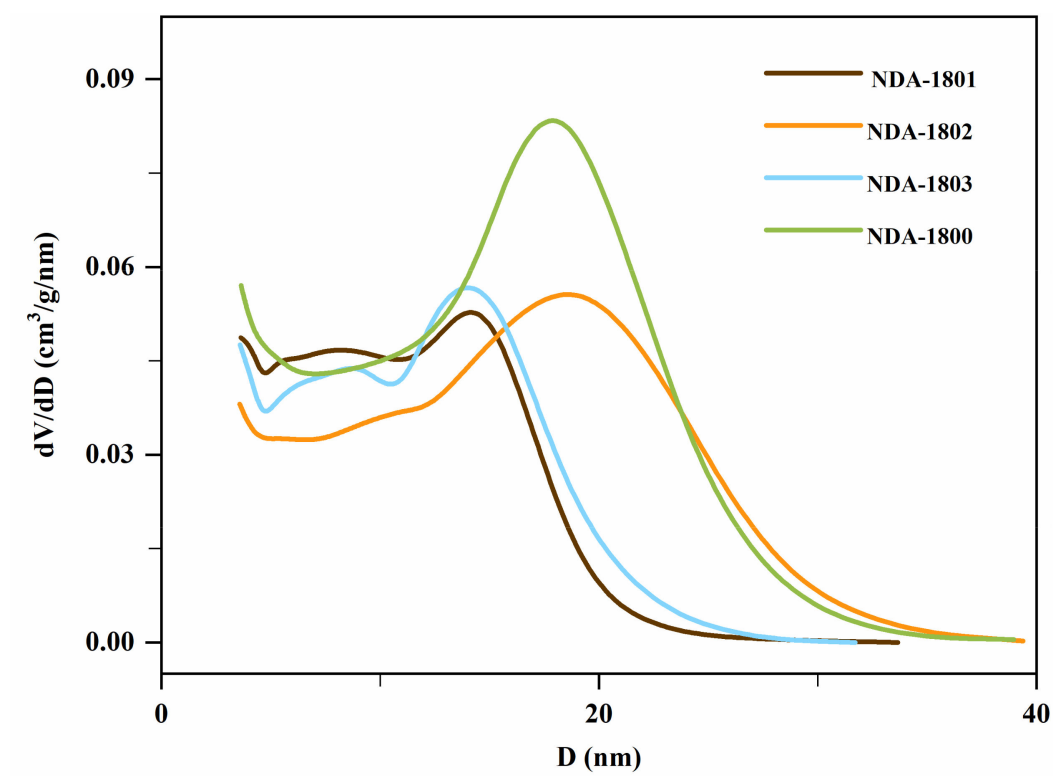

Figure 4. Mesopore diameter distribution of NDA-1800, NDA-1801, NDA-1802, and NDA-1803.

\subsection{Adsorption Kinetics}

The adsorption kinetic data were analyzed using pseudo-first-order and pseudosecond-order rate equations via nonlinear fitting [21,22]; Table 3 lists the corresponding parameters. The correlation coefficient $\left(\mathrm{R}^{2}\right)$ suggested that the pseudo-second-order rate equation was a better fitting model.

Figure 5 shows the adsorption kinetic curves of the three adsorbates on NDA-2 and NDA-3. Phenol rapidly reached equilibrium in approximately $0.5 \mathrm{~h}, \mathrm{ABS}$ acid reached 
equilibrium in approximately $8 \mathrm{~h}$, and RBB4 reached equilibrium in approximately $20 \mathrm{~h}$. The kinetics of the different adsorbates varied because the adsorption process on the inner surface of the resin is often very fast, and is mainly controlled by internal diffusion into the resin pores [23]. Owing to the relative size of the resin pores and the molecular size of phenol, the diffusion of phenol at the resin pore interface is similar to molecular diffusion in which there is free diffusion and a relatively high diffusion rate. However, RBB4 has a larger molecular volume, which leads to more frequent collisions with the pore wall, greater diffusion resistance, and a slower diffusion rate.

The rate constant, $\mathrm{k}_{2}$, of phenol adsorption was in the following order: NDA-2 > NDA-3, while this was the opposite for RBB4. The equilibrium adsorption capacities of NDA-2 for phenol and ABS acid were greater than those of NDA-3, while this was the opposite for RBB4. The pore diameter of NDA-2 was smaller than that of NDA-3, leading to a higher equilibrium adsorption capacity for micromolecules such as phenol and ABS acid. In contrast, NDA-3 had higher equilibrium adsorption capacity for the macromolecule RBB4. Therefore, the pore diameter distribution of the resin not only affected the adsorption rate, but also influenced the adsorption capacity of the resin for an adsorbate.

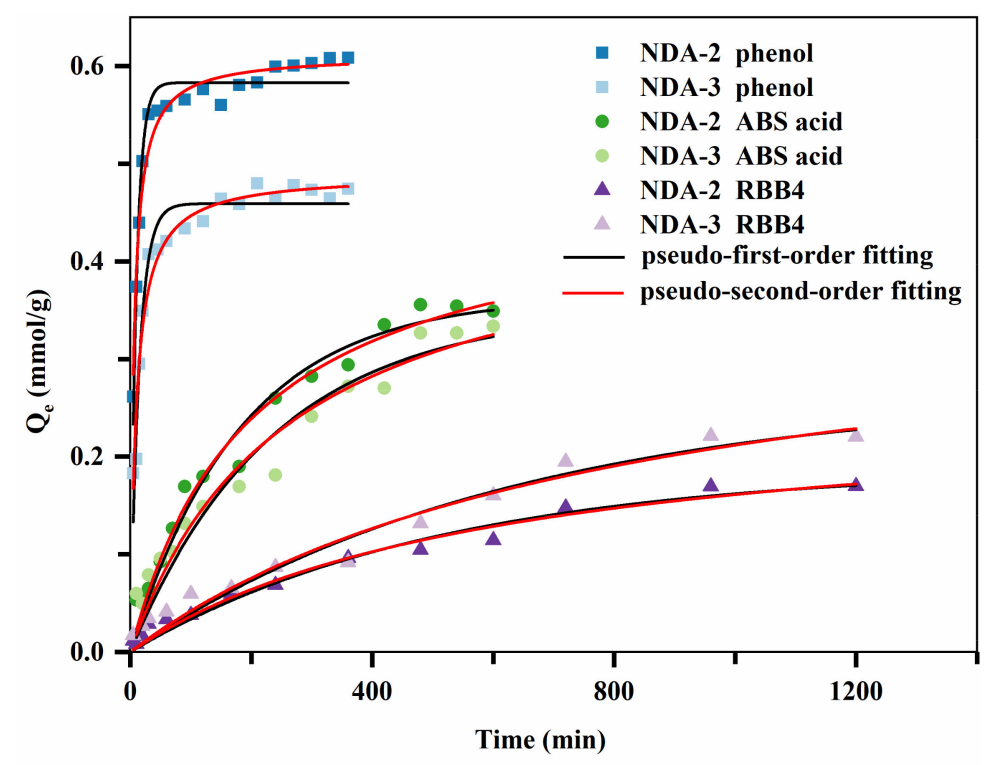

Figure 5. Adsorption kinetic curves of the three adsorbates.

Table 3. The corresponding parameters of the adsorption kinetic curves.

\begin{tabular}{|c|c|c|c|c|c|c|}
\hline & \multicolumn{3}{|c|}{ Pseudo-First-Order Rate Equation } & \multicolumn{3}{|c|}{ Pseudo-Second-Order Rate Equation } \\
\hline & $\begin{array}{c}\mathrm{Q}_{\mathrm{e}} \\
\left(\mathrm{L} \cdot \mathrm{mmol}^{-1}\right)\end{array}$ & $\begin{array}{c}\mathrm{K}_{\mathbf{1}} \\
\left(\mathrm{L} \cdot \mathrm{mmol}^{-1}\right)\end{array}$ & $\mathbf{R}^{2}$ & $\begin{array}{c}\mathrm{Q}_{\mathrm{e}} \\
\left(\mathrm{L} \cdot \mathrm{mmol}^{-1}\right)\end{array}$ & $\begin{array}{c}\mathrm{K}_{2} \\
\left(\mathrm{~L} \cdot \mathrm{mmol}^{-1}\right)\end{array}$ & $\mathbf{R}^{2}$ \\
\hline NDA-2 phenol & 0.583 & 0.102 & 0.963 & 0.611 & 0.284 & 0.969 \\
\hline NDA-3 phenol & 0.459 & 0.069 & 0.949 & 0.489 & 0.213 & 0.963 \\
\hline NDA-2 ABS acid & 0.364 & 0.005 & 0.974 & 0.477 & 0.011 & 0.980 \\
\hline NDA-3 ABS acid & 0.350 & 0.004 & 0.939 & 0.467 & 0.008 & 0.951 \\
\hline NDA-2 RBB4 & 0.267 & 0.002 & 0.957 & 0.384 & 0.003 & 0.958 \\
\hline NDA-3 RBB4 & 0.189 & 0.002 & 0.972 & 0.260 & 0.006 & 0.976 \\
\hline
\end{tabular}

\subsection{Static Adsorption Equilibrium}

We used a three-parameter multilayer adsorption model to describe the adsorption data [24]. The equation was as follows:

$$
Q_{e}=\frac{Q_{m} K_{1} C_{e}}{\left(1-K_{2} C_{e}\right)\left[1+\left(K_{1}-K_{2}\right) C_{e}\right]}
$$


where $C_{e}\left(\mathrm{mmol} \cdot \mathrm{L}^{-1}\right)$ is the equilibrium concentration of adsorbate, $Q_{e}\left(\mathrm{mmol} \cdot \mathrm{g}^{-1}\right)$ is the adsorption capacity of resin, $Q_{m}\left(\mathrm{mmol} \cdot \mathrm{g}^{-1}\right)$ is the maximum first-layer adsorption capacity of resin, $K_{1}\left(\mathrm{~L} \cdot \mathrm{mmol}^{-1}\right)$ is the first-layer adsorption equilibrium constant, and $K_{2}$ $\left(\mathrm{L} \cdot \mathrm{mmol}^{-1}\right)$ is the multilayer adsorption equilibrium constant. The three-parameter multilayer adsorption model can be used to describe almost all S-type adsorption isotherms, including the BET isotherm and the Freundlich isotherm, which are typical for gas adsorption and organic matter adsorption. The equilibrium adsorption isotherms are shown in Figure 6, and Table 4 summarizes the corresponding parameters. The adsorption isotherms of phenol were approximately straight lines in the concentration range of our study and could not be simulated by this model.

Figure 6a shows the adsorption isotherms of phenol on the four resins. The order of adsorption capacity was NDA-2 > NDA-1 > NDA-3 > NDA-4. The NDA-2 resin had the highest adsorption capacity because it had the largest specific surface area. Although NDA1 , NDA-3 and NDA-4 had similar specific surface areas, the pore diameter distribution of NDA-1 was mainly concentrated in the small mesopore region. This resin is suitable for the adsorption of micromolecules such as phenol. However, the opposite was true for NDA-4, which had lowest adsorption capacity for phenol.

Figure $6 \mathrm{~b}$ shows the adsorption isotherm of ABS acid on the four resins. The order of adsorption capacity was NDA-2 > NDA-3 > NDA-4 > NDA-1. Different from phenol, the adsorption capacity of NDA-1 for ABS acid was much lower than that of the other three resins. This was because the adsorption of ABS acid to NDA- 1 was affected by pore hindrance, making part of the pore volume unusable. One reason for this phenomenon is that the pore size of NDA-1 was smaller than that of the adsorbate molecule; thus, the molecule cannot be adsorbed within the resin pores. Second, in the process of diffusion from the surface to the inner channels of the resin, the adsorbate molecules are partly adsorbed onto the pore walls. This can cause the channels become blocked, preventing the adsorbate from passing through the channels. As can be seen from the pore diameter distribution diagram, the pore diameter of NDA- 1 was mainly distributed around approximately $3 \mathrm{~nm}$, this is 2-3 times larger than the diameter of ABS acid. Therefore, the adsorption of this molecule caused pore obstruction.

Figure $6 \mathrm{c}$ shows the adsorption isotherm of RBB4 on the four resins. The order of adsorption capacity was NDA-3 > NDA-4 > NDA-2 > NDA-1. Although NDA-2 had the largest specific surface area, its adsorption capacity was far lower than that of NDA-3 and NDA-4. This was because the NDA- 2 resin was also affected by pore hindrance. This effect was enhanced by the molecular aggregation of RBB4 [25]. Walker et al. [26] showed that the degree to which some acid dyes aggregate on the surface of activated carbon and bone charcoal could be greater than 10 molecules. Accordingly, it is understandable that the macromolecule RBB4 would experience pore hindrance on, NDA- 1 and NDA-2 owing to small pore diameters of these resins.
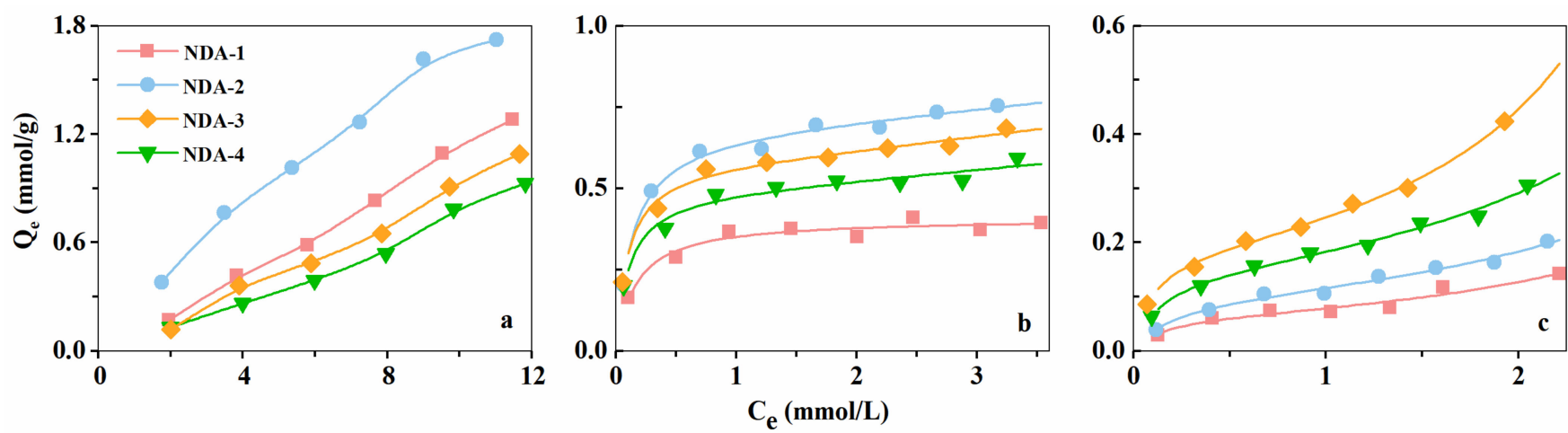

Figure 6. (a) Adsorption isotherms of phenol; (b) Adsorption isotherms of ABS acid; (c) Adsorption isotherms of RBB4. 
As shown in Figure 6, although NDA-4 and NDA-3 had similar specific surface areas, pore volumes and average pore diameters, the adsorption capacity of NDA-4 was lower than that of NDA-3 for the three adsorbates. This was because the pore diameter of NDA-4 was larger than that of the adsorbates. Thus, pore size that is either too small or too large is not conducive to improving the adsorption capacity of a resin, and there was an optimal adsorption pore size for specific adsorbates.

Table 4. The corresponding parameters of three-parameter multilayer adsorption model.

\begin{tabular}{|c|c|c|c|c|c|c|c|c|}
\hline \multirow[b]{2}{*}{ Resins } & \multicolumn{4}{|c|}{ ABS Acid } & \multicolumn{4}{|c|}{ RBB4 } \\
\hline & $\underset{\left(\mathrm{mmol}_{\mathrm{m}} \mathrm{g}^{-1}\right)}{\mathrm{Q}_{\mathrm{m}}}$ & $\begin{array}{c}\mathrm{K}_{1} \\
\left(\mathrm{~L} \cdot \mathrm{mmol}^{-1}\right)\end{array}$ & $\begin{array}{c}\mathrm{K}_{2} \\
\left(\mathrm{~L} \cdot \mathrm{mmol}^{-1}\right)\end{array}$ & $\mathbf{R}^{2}$ & $\underset{\left(\mathrm{mmol} \cdot \mathrm{g}^{-1}\right)}{\mathrm{Q}_{\mathrm{m}}}$ & $\begin{array}{c}\mathrm{K}_{1} \\
\left(\mathrm{~L} \cdot \mathrm{mmol}^{-1}\right)\end{array}$ & $\begin{array}{c}\mathrm{K}_{2} \\
\left(\mathrm{~L} \cdot \mathrm{mmol}^{-1}\right)\end{array}$ & $\mathbf{R}^{2}$ \\
\hline NDA-1 & 0.407 & 6.239 & 0.040 & 0.971 & 0.066 & 6.727 & 0.252 & 0.971 \\
\hline NDA-2 & 0.683 & 7.862 & 0.038 & 0.995 & 0.113 & 4.054 & 0.200 & 0.995 \\
\hline NDA-3 & 0.576 & 10.830 & 0.050 & 0.994 & 0.239 & 6.015 & 0.154 & 0.999 \\
\hline NDA-4 & 0.493 & 10.080 & 0.047 & 0.985 & 0.166 & 5.884 & 0.212 & 0.995 \\
\hline
\end{tabular}

The size distribution of the pores greatly influences the adsorption capacity of a resin. Only when the resin has a proper pore diameter can the adsorbate achieve good diffusion into the channels and be absorbed effectively. If the pore diameter is too large and the specific surface area is small, the resin will have a low adsorption capacity. If the pore diameter is too small, it will limit the diffusion of adsorbates and solvents, which enhances the shielding effect for molecules with larger diameters [27]. When the pore diameter of a micropore is less than several times the diameter of the adsorbate molecule, a potential shielding effect can occur. This can increase the interaction between the solid surface and gas molecules, thus enhancing adsorption [28]. Macropores, mesopores and micropores are typically categorized by pore diameters greater than $50 \mathrm{~nm}, 2-50 \mathrm{~nm}$, and less than $2 \mathrm{~nm}$, respectively. The surface of macropores contributes little to adsorption and only provides a channel for the diffusion of adsorbates and solvent. Mesopores can adsorb macromolecules and help micromolecules pass through the micropores.

Adsorption is related to the chemical structure of resin, regardless of the adsorption method. Regarding the adsorption mechanism, non-polar adsorbent resins adsorb molecules through van der Waals forces. By contrast, adsorption typically occurs via dipole-dipole and electrostatic interactions (including hydrogen bond and donor-acceptor interactions) for medium and strongly polar resins.

\subsection{Adsorption Properties of the Modified Resins}

The adsorption properties of the three amino-modified resins (NDA-1801, NDA-1802, and NDA-1803) for phenol, ABS acid and RBB4 were investigated at $288 \mathrm{~K}, 303 \mathrm{~K}$, and 318 $\mathrm{K}$ and were compared with NDA-1800. The results are presented in Figure 7 and Table S2 summarizes the corresponding parameters.

The phenol adsorption capacities of the four resins were similar at the three temperatures. The order of adsorption capacity was NDA-1800 $>$ NDA-1801 $\approx$ NDA-1803 $\approx$ NDA-1802. The adsorption of micromolecules such as phenol is mainly achieved through $\pi$ - $\pi$ and dipole-dipole interactions. The resin adsorption capacity was greatly affected by the surface of the resin, and no ion exchange occurred. Compared with NDA-1800, the specific surface areas of the three amine-modified resins were decreased; thus, the adsorption capacities were lower. However, the specific surface area of the three amino-modified resins were similar, and their adsorption capacities were not significantly different.

The ABS acid adsorption capacity of the four resins was in the order of NDA-1801 $\approx$ NDA-1803 > NDA-1800 > NDA-1802 at all three temperatures. Compared with NDA1800, the adsorption capacities of NDA-1801 and NDA-1803 were increased because of the increased polarity of the resins and the enhanced dipole-dipole and ion exchange interactions that occurred between the resin and the adsorbate, even though the specific 
surface areas were reduced after amination. The pore diameter distribution was slightly reduced, which was suitable for the adsorption of ABS acid molecules and increased the adsorption capacity. The adsorption capacity of the resin modified with secondary amines decreased slightly owing to the increased pore size distribution and the decreased specific surface area.

The RBB4 adsorption capacity of the four resins at all three temperatures was in the order of NDA-1802 $>$ NDA-1803 $\approx$ ND-1801 $>$ NDA-1800. Compared with NDA-1800, the adsorption capacities of the amine-modified resins markedly improved. The adsorption capacity of the secondary amine resin (NDA-1802) increased the most. This was because the presence of the polar functional group could be used for ion exchange and because the resin pore size remained large. The adsorption capacities of NDA-1801 and NDA-1803 increased owing to the presence of polar functional groups.
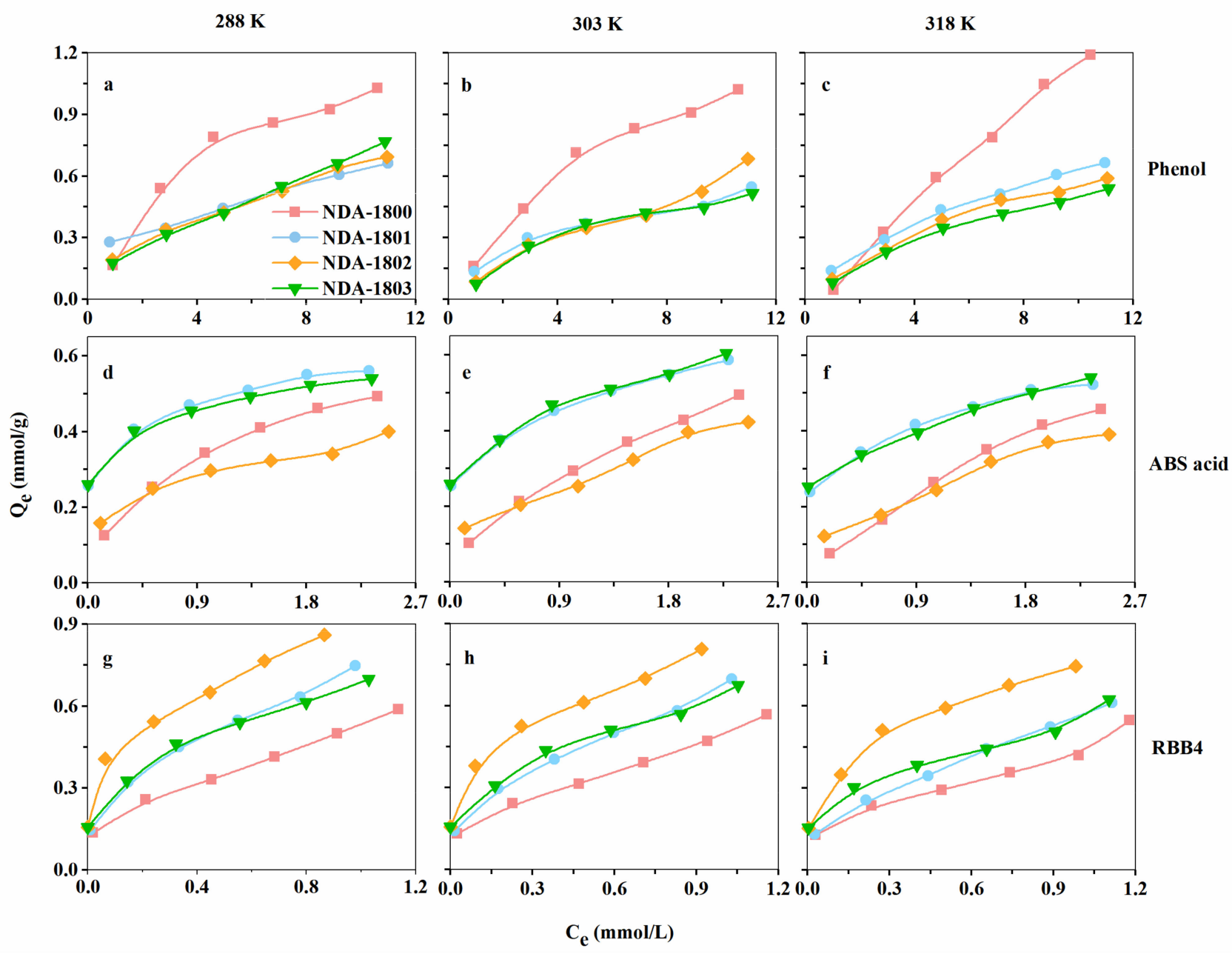

Figure 7. (a) Adsorption isotherms of phenol at $288 \mathrm{~K}$; (b) Adsorption isotherms of phenol at $303 \mathrm{~K}$; (c) Adsorption isotherms of phenol at $318 \mathrm{~K}$; (d) Adsorption isotherms of ABS acid at $288 \mathrm{~K}$; (e) Adsorption isotherms of ABS acid at $303 \mathrm{~K}$; (f) Adsorption isotherms of ABS acid at $318 \mathrm{~K}$; (g) Adsorption isotherms of RBB4 at $288 \mathrm{~K}$; (h) Adsorption isotherms of RBB4 at $303 \mathrm{~K}$; (i) Adsorption isotherms of RBB4 at $318 \mathrm{~K}$.

\section{Conclusions}

We have synthesized a series of mesoporous resins with different pore size distributions via suspension polymerization. These resins, which were suitable for the adsorption of macromolecules. The adsorption kinetics data were well-fitted by a pseudo-second-order rate equation, and the adsorption equilibrium data were described by a three-parameter multilayer adsorption model. The adsorption of small molecules reached equilibrium 
quicker than large molecules, and resins with smaller pores had a lower adsorption capacity for large molecules because of the pore blockage effect. NDA-1 and NDA-2 could efficiently adsorb phenol and ABS acid, while NDA-3 could efficiently adsorb RBB4. The resins were modified by amine groups. The presence of polar functional groups led to more efficient RBB4 adsorption, while the decreased specific surface areas led to decreased phenol adsorption capacities. Thus, a composite functional adsorbent resin with an improved ability to adsorb the macromolecule RBB4 was obtained. These mesoporous resins are promising candidates for application in removing organic contaminants from wastewater.

Supplementary Materials: The following are available online, Figure S1: Characterization of the adsorbates, Table S1: The reagents used of synthetic resins, Figure S2: N2 adsorption isotherms of NDA-1 (a), NDA-2 (b), NDA-3 (c) and NDA-4 (d) resins at 77K (logarithmic scale (p/p0)), Figure S3: The infrared spectra of the four resins, Table S2: The corresponding parameters of three-parameter multilayer adsorption model.

Author Contributions: Conceptualization, W.L. and Y.D.; methodology, W.L. and J.T.; validation, S.W.; formal analysis, Y.Z.; investigation, W.L.; writing-original draft preparation, Y.Z.; writingreview and editing, Y.Z. and W.L.; visualization, Y.Z. and W.L.; supervision, L.B.; project administration, L.B. and S.W. All authors have read and agreed to the published version of the manuscript.

Funding: This work was supported by The National Key Research and Development Program of China (2018YFC1801606), National Natural Science Foundation of China (51808267) and Independent Research Project of Key Laboratory of Environmental Engineering of Jiangsu Province (ZZ2020002).

Institutional Review Board Statement: Not applicable.

Informed Consent Statement: Not applicable.

Data Availability Statement: Not applicable.

Conflicts of Interest: The authors declare no conflict of interest.

\section{References}

1. Vijayaraghavan, K.; Ashokkumar, T. Characterization and evaluation of reactive dye adsorption onto Biochar Derived from Turbinaria conoides Biomass. Environ. Prog. Sustain. Energy 2019, 38, 13143. [CrossRef]

2. Jothirani, R.; Kumar, P.S.; Saravanan, A.; Narayan, A.S.; Dutta, A. Ultrasonic modified corn pith for the sequestration of dye from aqueous solution. J. Ind. Eng. Chem. 2016, 39, 162-175. [CrossRef]

3. Malik, A.; Rahman, M.; Ansari, M.I.; Masood, F.; Grohmann, E. Environmental protection strategies: An overview. Environ. Prot. Strateg. Sustain. Dev. 2012, 1-34. [CrossRef]

4. Fu, Y.; Jiang, J.; Chen, Z.; Ying, S.; Wang, J.; Hu, J. Rapid and selective removal of Hg(II) ions and high catalytic performance of the spent adsorbent based on functionalized mesoporous silica/poly(m-aminothiophenol) nanocomposite. J. Mol. Liq. 2019, 286, 110746. [CrossRef]

5. Yadav, V.B.; Gadi, R.; Kalra, S. Clay based nanocomposites for removal of heavy metals from water: A review. J. Environ. Manag. 2019, 232, 803-817. [CrossRef]

6. Issabayeva, G.; Aroua, M.K.; Sulaiman, N.M. Study on palm shell activated carbon adsorption capacity to remove copper ions from aqueous solutions. Desalination 2010, 262, 94-98. [CrossRef]

7. Tsyurupa, M.P.; Blinnikova, Z.K.; Davidovich, Y.A.; Lyubimov, S.E.; Naumkin, A.V.; Davankov, V.A. On the nature of "functional groups" in non-functionalized hypercrosslinked polystyrenes. React. Funct. Polym. 2012, 72, 973-982. [CrossRef]

8. Xiao, G.; Wen, R.; Wei, D.; Wu, D. Effects of the steric hindrance of micropores in the hyper-cross-linked polymeric adsorbent on the adsorption of p-nitroaniline in aqueous solution. J. Hazard. Mater. 2014, 280, 97-103. [CrossRef] [PubMed]

9. Sun, Y.; Chen, J.; Li, A.; Liu, F.; Zhang, Q. Adsorption of resorcinol and catechol from aqueous solution by aminated hypercrosslinked polymers. React. Funct. Polym. 2005, 64, 63-73. [CrossRef]

10. Salehi, E.; Shafie, M. Adsorptive removal of acetaldehyde from water using strong anionic resins pretreated with bisulfite: An efficient method for spent process water recycling in petrochemical industry. J. Water Process. Eng. 2020, 33, 101025. [CrossRef]

11. Mansha, M.; Waheed, A.; Ahmad, T.; Kazi, I.W.; Ullah, N. Synthesis of a novel polysuccinimide based resin for the ultrahigh removal of anionic azo dyes from aqueous solution. Environ. Res. 2020, 184, 109337. [CrossRef] [PubMed]

12. Tsyurupa, M.P.; Davankov, V.A. Porous structure of hypercrosslinked polystyrene: State-of-the-art mini-review. React. Funct. Polym. 2006, 66, 768-779. [CrossRef]

13. Kuang, W.; Li, H.; Huang, J.; Liu, Y.-N. Tunable porosity and polarity of the polar hyper-cross-linked resins and the Enhanced adsorption toward phenol. Ind. Eng. Chem. Res. 2016, 55, 12213-12221. [CrossRef] 
14. $\mathrm{Wu}, \mathrm{Y} . ; \mathrm{Li}, \mathrm{Z}$; $\mathrm{Xi}, \mathrm{H}$. Influence of the microporosity and surface chemistry of polymeric resins on adsorptive properties toward phenol. J. Hazard. Mater. 2004, 113, 131-135. [CrossRef]

15. Li, A.; Zhang, Q.; Chen, J.; Fei, Z.; Long, C.; Li, W. Adsorption of phenolic compounds on Amberlite XAD-4 and its acetylated derivative MX-4. React. Funct. Polym. 2001, 49, 225-233. [CrossRef]

16. Huang, J.; Zha, H.; Jin, X.; Deng, S. Efficient adsorptive removal of phenol by a diethylenetriamine-modified hypercrosslinked styrene-divinylbenzene (PS) resin from aqueous solution. Chem. Eng. J. 2012, 195-196, 40-48. [CrossRef]

17. Li, Q.; Lu, X.; Shuang, C.; Qi, C.; Wang, G.; Li, A.; Song, H. Preferential adsorption of nitrate with different trialkylamine modified resins and their preliminary investigation for advanced treatment of municipal wastewater. Chemosphere 2019, 223, 39-47. [CrossRef] [PubMed]

18. Shields, S.L.E. Powder Surface Area and Porosity; Chapman and Hall: New York, NY, USA, 1991; p. 119.

19. Shuang, C.; Pan, F.; Zhou, Q.; Li, A.; Li, P.; Yang, W.J.I.; Research, E.C. Magnetic polyacrylic anion exchange resin: Preparation, characterization and adsorption behavior of humic acid. Ind. Eng. Chem. Res. 2012, 51, 4380-4387. [CrossRef]

20. Horikawa, T.; Do, D.D.; Nicholson, D. Capillary condensation of adsorbates in porous materials. Adv. Colloid Interface Sci. 2011, 169, 40-58. [CrossRef] [PubMed]

21. Lagergren, S.K. About the theory of so-called adsorption of solution substances. Sven. Vetenskapsakad. Handingarl 1898, 24, 1-39.

22. Ho, Y.S.; McKay, G.; Pollution, S. Sorption of Copper(II) from aqueous solution by peat. Water Air Soil Pollut. 2004, 158, 77-97. [CrossRef]

23. Zhang, J.; Zhu, C.; Sun, H.; Peng, Q. Separation of glycolic acid from glycolonitrile hydrolysate using adsorption technology. Colloids Surf. A Physicochem. Eng. Asp. 2017, 520, 391-398. [CrossRef]

24. Wang, J.; Huang, C.P.; Allen, H.E.; Cha, D.K.; Kim, D.-W. Adsorption characteristics of dye onto sludge particulates. J. Colloid Interface Sci. 1998, 208, 518-528. [CrossRef]

25. Yang, W.; Xue, X.; Zheng, F.; Yang, X. Importance of surface area and pore size distribution of resin for organic toxicants adsorption. Sep. Sci. Technol. 2011, 46, 1321-1328. [CrossRef]

26. Walker, G.M.; Weatherley, L. Adsorption of dyes from aqueous solution-The effect of adsorbent pore size distribution and dye aggregation. Chem. Eng. J. 2001, 83, 201-206. [CrossRef]

27. Huang, J. Molecular sieving effect of a novel hyper-cross-linked resin. Chem. Eng. J. 2010, 165, 265-272. [CrossRef]

28. Long, C.; Lu, J.; Li, A.; Hu, D.; Liu, F.; Zhang, Q. Adsorption of naphthalene onto the carbon adsorbent from waste ion exchange resin: Equilibrium and kinetic characteristics. J. Hazard. Mater. 2008, 150, 656-661. [CrossRef] 